\title{
THE STRUCTURE OF ECHINATIC ACID
}

N. P. Kir'yalov and V. F. Bogatkina

Khimiya Prirodnykh Soedinenii, Vol. 5, No. 5, pp. 447-448, 1969

As shown previously $[1,2]$, echinatic acid $\mathrm{C}_{30} \mathrm{H}_{46} \mathrm{O}_{5}$ with $\mathrm{mp} 298-300^{\circ} \mathrm{C}$, mol. wt. 500 belongs to the $\beta$-amyrin series. On the basis of its mass and NMR spectra it may be assumed that echinatic acid contains three hydroxyl groups. In the $\tau$ 7.9-8 region there are nine protons of three acetyl groups the secondary nature of which is confirmed by signals with a total area of $3 \mathrm{H}(\tau 5.3-5.9)$ corresponding to the protons of acetyl groups.

In the NMR spectrum there are signals in the $\tau 4.6$ and 4.9 regions (two protons) corresponding to olefinic protons, apparenty in ring $C$, in which the presence of two conjugated double bonds is confirmed by the UV spectrum: $\lambda_{\max }$ $280-282(\log \varepsilon 3-3.3)$.

The tertiary nature of the $\mathrm{COOH}$ group is shown by the ready splitting off of $\mathrm{CO}_{2}$ in the saponification of the triketo derivative of the methyl ester of echinatic acid ( $\mathrm{mp} 220-225^{\circ} \mathrm{C}$ ). This reaction simultaneously shows that one of the hydroxyl groups is adjacent to the carboxyl group. A second hydroxyl group is possibly in the $\gamma$ position with respect to the carboxyl since the oxidation of the acetate of echinatic acid with $\mathrm{CrO}_{3}$ forms a substance having a lactone group (band at $1780 \mathrm{~cm}^{-1}$ in the IR spectrum). At the same time, the two $\mathrm{OH}$ groups mentioned are not adjacent to one another, since echinatic acid does not contain an $\alpha$-glycol system.

The oxidation of the triacetate of the methyl ester of echinatic acid with $\mathrm{SeO}_{2}$ first gives a heteroangular diene with $\mathrm{mp} 192^{\circ} \mathrm{C}$; UV spectrum $\lambda_{\max } \mathrm{mu}: 258,249,240$; IR spectrum, $\mathrm{cm}^{-1}: 1735$ (CO of ester groups). Subsequently, the substance with $\mathrm{mp} 192^{\circ} \mathrm{C}$ was oxidized by the $\mathrm{SeO}_{2}$ to a dienedione with $\mathrm{mp} 212-214^{\circ} \mathrm{C}$; UV spectrum, $\lambda_{\max } \mathrm{m} \mu: 280$ (on 12-fold dilution); IR spectrum, $\mathrm{cm}^{-1}$ : 1625 (double bond), 1665 (conjugated CO group of a six-membered ring), 1700 (CO of a keto group), and 1735 (CO of ester groups).

Echinatic acid does not form a bromolactone under the usual conditions (like morolic acid) [3], which is due to the absence of a $\mathrm{COOH}$ group at $\mathrm{C}_{(17)}$ or to steric hindrance.

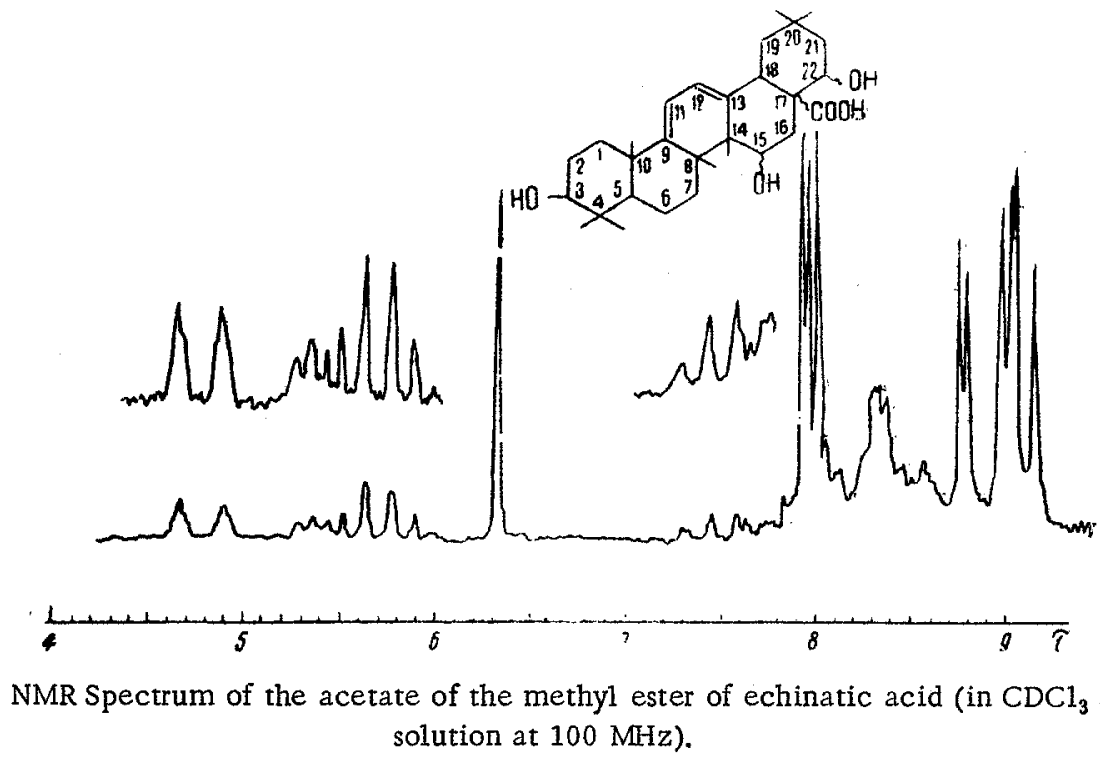

The reactions of echinatic acid and its derivatives are explained in a comparatively simple manner if it is assumed that one of the $\mathrm{OH}$ groups is located at $\mathrm{C}_{(3)}$ and the other two at $C_{(15)}$ and $C_{(22)}$ or at $C_{(16)}$ and $C_{(21)}$ (figure) and the $\mathrm{COOH}$ group at $\mathrm{C}_{(17)}$.

\section{REFERENCES}

1. N. P. Kiryalov and T. N. Naugol'naya, ZhoKh, 34, 8, 1963.

2. N. P. Kir'yalov, Questions of the Study and Use of Licorice in the USSR [in Russian], Leningrad, p. $123,1966$.

3. J. Simonsen and W. C. J. Ross, The Terpenes, 5, 209, 1957. 